\title{
Cannabis legalization: Did we make a mistake? Update 2019
}

\author{
Marco Leyton, PhD
}

In the fall of 2015, I wrote a JPN editorial endorsing the proposed Canadian legalization of cannabis for nonmedical purposes. ${ }^{1}$ This brief comment elicited one of the largest responses of my career. Strong opinions were expressed, with roughly half agreeing, the other half not. Members of this journal's editorial board were no less divided, fostering the first use of a statement that "The views expressed in this editorial are those of the author(s)." See above. Now, nearly 4 years later, I examine how the endorsement holds up. The 2 primary concerns in 2015 continue to dominate discussions: potential increases in car accidents and an aggravation of cannabis-related psychoses.

\section{Has cannabis legalization increased traffic fatalities?}

The best data come from the United States, where some jurisdictions have had medical marijuana laws (MML) since the 1990s and legalization of nonmedical use since 2012. In these states, traffic fatalities decreased following the institution of MML and increased following legalization. ${ }^{2,3}$ The increases lasted no more than a year, averaged an additional 1.1 fatalities per million, and mirrored changes in states without legalization $^{2,3}$ (Box 1a). A recent Canadian study bolsters these findings. In drivers treated at trauma centres $(n=2318)$, there was no association between responsibility for the crash and blood $\Delta$-9-tetrahydrocannabinol (THC) levels $<5 \mathrm{ng} / \mathrm{mL}$ and only a weak, nonsignificant association with levels $\geq 5 \mathrm{ng} / \mathrm{mL}(p=0.35)^{13}$ (Box $\left.1 \mathrm{~b}\right)$.

\section{Does cannabis use cause psychosis?}

There is now stronger evidence of a link between adolescent (but not adult) cannabis use and psychosis. ${ }^{14-17}$ The effect size continues to look small or nonexistent for sporadic use, ${ }^{16,18,19}$ but larger for vulnerable adolescents ${ }^{20,21}$ who use high-potency cannabis on a daily or near daily basis ${ }^{17,20,21}$ (Box 1c). In part, the association appears to reflect overlapping genetics, ${ }^{18,19,21}$ with average age of cannabis use initiation preceding the onset of psychosis. ${ }^{14}$

It remains unclear whether the cannabis-psychosis association includes a causal component. If it does, one estimate is that daily adolescent use could be a contributing factor for up to $20 \%$ of new psychotic disorder cases. ${ }^{17}$ Establishing a causal link (if it exists) will be challenging (Box 1d). The great majority of cannabis users do not develop psychotic disorders, and most people with psychoses were not frequent cannabis users. ${ }^{17}$ One possibility suggested by Di Forti and colleagues is that adolescent cannabis use might be a necessary, but not sufficient, cause in a subset of individuals. ${ }^{17,22}$ The evidence supporting this position is not conclusive, but continues to accumulate and should not be ignored.

\section{Does legalization increase cannabis use?}

If a causal link between cannabis and psychosis becomes established, the implications for legalization are less than commonly implied. Heavy cannabis use is associated with greater psychosis risk only when use begins in adolescence. It is therefore critical to note that there remains no compelling evidence that legalization increases adolescent cannabis use. In the United States, legalization has been associated with increased use by adults, but not by youth. ${ }^{8-10}$ Preliminary observations indicate that the same is happening in Canada. During the 3 months following legalization in October 2018, cannabis use on 1 or more occasions increased in 1 group only: men aged $45-64$ years (9\% to $14 \%) .{ }^{11}$ Cannabis use by females and males in other age groups remained unchanged, as did the prevalence of frequent use. ${ }^{11}$

Definitions

Decriminalization: changing cannabis use from a criminal to a civil offense.

Legalization: removal of punitive sanctions for cannabis use.

Correspondence to: M. Leyton, Department of Psychiatry, Ludmer Research \& Training Building, McGill University, 1033 Pine Ave. West, Montreal, QC H3A 1A1; marco.leyton@mcgill.ca 


\section{Box 1: Notes}

a. In contrast to these reports, ${ }^{2,3}$ one analysis suggests that there was a sustained increase in Colorado traffic fatalities between 2013 and 2017 following the opening of legal retail stores. ${ }^{4}$ In part, this reflected population increases, switching to a data source that provided $100 \%$ of fatalities, and similar traffic fatality changes in states without cannabis legalization. ${ }^{2,3}$ These factors noted, traffic fatality data from Colorado and elsewhere will need to be followed further.

b. On average, whole blood $\Delta$-9-tetrahydrocannabinol (THC) levels peak at $100 \mathrm{ng} / \mathrm{mL}$ within 15 minutes of smoking a typical cannabis cigarette, dropping to $<2 \mathrm{ng} / \mathrm{mL}$ within 4 hours, at which point the psychotropic effects have dissipated.

c. Few would endorse the daily use of high-potency cannabis for nonmedical purposes any more than they would endorse daily binge drinking.

d. The mechanism by which cannabis use might increase risk for psychosis remains unknown, but studies in laboratory animals and humans suggest that extensive adolescent cannabis ingestion can alter endocannabinoid, ${ }^{5}$ monoamine ${ }^{6}$ and glutamate transmission (Leyton et al., unpublished observations).

e. The magnitude of drug use cycles that occur independent of public policies underscores the caution needed when attempting to attribute a change in population behaviour to a single factor.

f. Cannabis use has other risks also. ${ }^{1,7}$ Since legalization has had minimal effects on cannabis use ${ }^{8-11}$ these outcomes are no more likely to be affected than the primary issues discussed here, traffic fatalities and psychosis.

g. Alcohol prohibition in the early 20th century decreased consumption in some quarters ${ }^{12}$ but ultimately was rejected for converging social, political and economic reasons. These included increased gang violence, poisonings from adulterated alcohol, a loss of tax revenue, corruption and the criminalization of otherwise law-abiding citizens.

The lack of increased cannabis use by Canadian youth is all the more striking since their use markedly decreased during the 5 years leading up to 2015 (past year use decreased by $28 \%$; daily use decreased by $90 \%$; age of first use increased by 0.5 years).$^{23}$ If cannabis use starts to rise again, it might be a delayed effect of legalization, but the weight of evidence suggests that it will be unrelated (Box 1e and f).

\section{Has everything gone smoothly?}

Not all aspects of cannabis legalization in Canada have gone smoothly. Indigenous communities were not adequately consulted. ${ }^{24}$ The responsibility to design and implement policies has been placed on provinces and municipalities during a period when many expected to focus on repairing infrastructure (e.g., roads, bridges, sewage). The collected tax revenue (\$186 million in the first 5 and a half months and expected to increase $)^{25}$ will assuage some concerns, but it remains unclear how it will be spent, including how much will be used for substance use prevention and treatment.

Arrest rates for cannabis possession have decreased, as anticipated. In US states with decriminalization for all, arrest rates have decreased for both adults and youth. ${ }^{26}$ In states with legalization for adults only, arrest rates decreased for adults but not youth. ${ }^{26}$ Post-legalization arrest rate data in Canada are not yet available, but in the years leading up to legalization (2013-2017) both adult and youth arrest rates decreased. ${ }^{27}$ If post-legalization arrest rates for youth do not decline more than the decrease in cannabis use, ${ }^{10,11}$ a potential solution is to decriminalize cannabis possession for youth while continuing to restrict legal sales to adults. ${ }^{26}$

Not all cannabis-using Canadians purchase the substance from government-authorized sellers. This reflects a number of factors. Legal sellers cannot keep up with demand, their product costs more than on the street, and the range of products offered is limited. ${ }^{28}$ For these reasons alone, the black market continues to thrive. Like many effects of complex public policies, this is a double-edged sword. On the one hand, there is a loss of tax revenue; on the other hand, if the black market loses few customers, they will have reduced incentive to increase the selling of other potentially more dangerous substances. These effects need more study, but to date, increased legal access to cannabis has been associated with fewer opioid deaths rather than more. ${ }^{29}$

As the legal cannabis market expands, it will serve us well to recall misconduct by the legal tobacco, alcohol and opioid industries. These for-profit companies have shown inadequate concern for the harm done and find little incentive to do more. Purdue Pharmaceuticals, for example, recently announced their plans for undeveloped countries, where they look forward to fighting "opiophobia." 30 The black market often behaves worse, but we can and should expect more.

\section{Conclusion}

The past 4 years have brought better quality evidence in 3 important areas. First, there is better evidence that cannabis legalization does not lead to large or sustained increases in traffic accidents. Second, there is better evidence of an association between adolescent cannabis use and psychoses. Third, there is better evidence that legalization does not increase adolescent cannabis use. The absence of these feared effects has been accompanied by anticipated positive outcomes: decreased arrests of cannabis users and generated tax revenue.

It will take a decade or more before we understand the effects of legalization in full. However, not everything about this issue is new. In their comprehensive 1973 report, Gerald Le Dain, Heinz Lehmann and others concluded that the criminalization of cannabis (and nonmedical drug use in general) was a failed policy, aggravating social ills without decreasing use $^{31}$ (Box 1g). Many consider their analysis still valid..$^{32-37}$

Affiliations: From the Departments of Psychiatry and Psychology, McGill University; the Department of Neurology \& Neurosurgery, Montreal Neurological Institute, McGill University; the Center for Studies in Behavioral Neurobiology, Concordia University; and the Research Unit on Children's Psychosocial Maladjustment, Université de Montréal, Montreal, Que., Canada.

\section{References}

1. Leyton M. Legalizing marijuana. J Psychiatry Neurosci 2016;41:75-6.

2. Lane TJ, Hall W. Traffic fatalities within US states that have legalized recreational cannabis sales and their neighbours. Addiction 2019;114:847-56.

3. Aydelotte JD, Brown LH, Luftman KM, et al. Crash fatality rates after recreational marijuana legalization in Washington and Colorado. Am J Public Health 2017;107:1329-31 
4. Rocky Mountain High Density Trafficking Area Strategic Intelligence Unit. The legalization of marijuana in Colorado: the impact, Vol 5. RMHDTA; 2018.

5. Kruse LC, Cao JK, Viray K, et al. Voluntary oral consumption of $\Delta 9$-tetrahydrocannabinol by adolescent rats impairs reward-predictive cue behaviors in adulthood. Neuropsychopharmacology 2019;44:1406-14.

6. Bambico FR, Nguyen N-T, Katz N, et al. Chronic exposure to cannabinoids during adolescence but not during adulthood impairs emotional behavior and monoaminergic neurotransmission. Neurobiol Dis 2010;37:641-55.

7. Memedovich KA, Dowsett LE, Spackman E, et al. The adverse health effects and harms related to marijuana use: an overview review. CMAJ Open 2018;16:E339-46.

8. Cerdá M, Wall M, Feng T, et al. Association of state recreational marijuana laws with adolescent marijuana use. JAMA Pediatr 2017;171:142-9.

9. Cerdá M, Sarvet AL, Wall M, et al. Medical marijuana laws and adolescent use of marijuana and other substances: alcohol, cigarettes, prescription drugs, and other illicit drugs. Drug Alcohol Depend 2018;183:62-8.

10. Anderson DM, Hansen B, Rees DI, et al. Association of marijuana laws with teen marijuana use: new estimates from the youth risk behavior surveys. JAMA Pediatr 2019 Jul 8. doi: 10.1001/jamapediatrics .2019.1720. [Epub ahead of print]

11. Statistics Canada. National Cannabis Survey, first quarter 2019. Ottawa, ON: Statistics Canada; 2019. Available: https://www150. statcan.gc.ca/n1/en/daily-quotidien/190502/dq190502a-eng. pdf?st=TQEzeqzW (accessed 2019 May 5).

12. Smart AG, Ogborne AC. Northern spirits: drinking in Canada then and now. Toronto, ON: Addiction Research Foundation; 1986. Available: https://archive.org/details/northernspiritsd00smar_0/page/n1 (accessed 2019 Jul. 15).

13. Brubacher JR, Chan H, Erdelyi S, et al. Cannabis use as a risk factor for causing motor vehicle crashes: a prospective study. Addiction 2019 May 20. doi: 10.1111/add.14663. [Epub ahead of print].

14. Bourque J, Afzali MH, Conrod PJ. Association of cannabis use with adolescent psychotic symptoms. JAMA Psychiatry 2018;75:864-6.

15. Jones HJ, Gage SH, Heron J, et al. Association of combined patterns of tobacco and cannabis use in adolescence with psychotic experiences. JAMA Psychiatry 2018;75:240-6.

16. Vaucher J, Keating BJ, Lasserre AM, et al. Cannabis use and risk of schizophrenia: a Mendelian randomization study. Mol Psychiatry 2018;23:1287-92.

17. Di Forti M, Quattrone D, Freeman TP, et al. The contribution of cannabis use to variation in the incidence of psychotic disorders across Europe (EU-GEI): a multicenter case-control study. Lancet Psychiatry 2019;6:427-36.

18. Gage SH, Jones HJ, Burgess S, et al. Assessing causality in associations between cannabis use and schizophrenia risk: a two-sample Mendelian randomization study. Psychol Med 2017;47:971-80.

19. Pasman JA, Verwij KJH, Gerring Z, et al. GWAS of lifetime cannabis use reveals new risk loci, genetic overlap with psychiatric traits, and a causal influence of schizophrenia. Nat Neurosci 2018;21:1161-70.

20. Kendler KS, Ohlsson H, Sundquist J, et al. Prediction of onset of substance-induced psychotic disorder and its progression to schizophrenia in a Swedish national sample. Am J Psychiatry 2019 May 6: appiajp201918101217. [Epub ahead of print].
21. Karcher NR, Barch DM, Demers CH, et al. Genetic predisposition vs individual-specific processes in the association between psychoticlike experiences and cannabis use. JAMA Psychiatry 2019;76:87-94.

22. Di Forti M, Morgan C, Selten JP, et al. Authors' reply. Lancet Psychiatry 2019;6:466-7.

23. Wallingford S, Konefal S, Young MM; Student Drug Use Surveys Working Group. Cannabis use, harms and perceived risks among Canadian students. Ottawa, ON: Canadian Centre on Substance use and Addiction; 2019.

24. Wesley JJ. Cannabis legalization and colonial legacies. In: High Time: The Legalization and Regulation of Cannabis in Canada. Potter A Weinstock D (eds). Montreal \& Kingston, London, Chicago: McGillQueen's University Press; 2019. pp. 35-49.

25. Statistics Canada. Government revenues from the sale of cannabis, March 2019. Ottawa, ON: Statistics Canada; 2019. Available: https:// www150.statcan.gc.ca/n1/en/daily-quotidien/190619/dq190619e -eng.pdf?st=A_pCnyVP (accessed 2019 Jul. 1).

26. Plunk AD, Peglow SL, Harrell PT, et al. Youth and adult arrests for cannabis possession after decriminalization and legalization of cannabis. JAMA Pediatr 2019 Jun 17. doi: 10.1001/jamapediatrics .2019.1539 [Epub ahead of print].

27. Statistics Canada. Table 35-10-017701. Incident based crime statistics, by detailed violations, Canada, provinces, territories and Census Metropolitan Areas. Ottawa, ON: Statistics Canada; 2019. Available: https: / / www150.statcan.gc.ca/t1/tbl1/en/tv.action?pid=3510017 701\&pickMembers \%5B0\%5D=1.1\&pickMembers\%5B1\%5D=2.176 (accessed 2019 Jul. 15)

28. Sen A, Wyonch R. Technology, black markets, and retail marijuana. In: High Time: The Legalization and Regulation of Cannabis in Canada. Potter A, Weinstock D (eds). Montreal \& Kingston, London, Chicago: McGill-Queen's University Press; 2019. pp. 151-64.

29. Hall W, West R, Mardsen J, et al. It is premature to expand access to medicinal cannabis in hopes of solving the US opioid crisis. Addiction 2018;113:987-8.

30. Ryan H, Girion L, Glover S. Oxycontin goes global - "We're only just getting started." Los Angeles Times; 2016 Dec. 18.

31. Le Dain G, Campbell IL, Lehmann HE, et al. Final report of the commission of inquiry into the non-medical use of drugs. Ottawa, ON: Crown Copyrights, Information Canada; 1973.

32. Annan K. Lift the ban! Kofi Annan on why it is time to legalize drugs. Spiegel Online; 2016. Available: http://www.spiegel.de/international /world/kofi-annan-on-why-drug-bans-are-ineffective-a-1078402 .html (accessed 2016 Feb. 22).

33. Godlee F, Hurley R. The war on drugs has failed: Doctors should lead calls for drug policy reform. BMJ 2016;355:i6067.

34. The Lancet Psychiatry. Drug policy: getting over the 20th century. Lancet Psychiatry 2016;3:187.

35. Nature editorial. On a downer. The United Nations has chosen to keep the war on drugs going — but can't win. Nature 2016;532:413-4.

36. Potter A, Weinstock D, editors. High Time: The Legalization and Regulation of Cannabis in Canada. Montreal \& Kingston, London, Chicago: McGill-Queens University Press; 2019.

37. Babor T, Caulkins J, Fischer B, et al. Drug policy and the public good: a summary of the second edition. Addiction 2019 Jul. 11. doi: 10.1111/add.14734 [Epub ahead of print]. 